\title{
Vídeo espontáneo infantil en contextos familiares y cine de animación en contextos escolares. Dos investigaciones preliminares en Granada y Tegucigalpa
}

\author{
Children's spontaneous video in family contexts and animated \\ cinema in school contexts. Two preliminary enquires in Granada and \\ Tegucigalpa
}

\author{
Ricardo MARÍN VIADEL. Universidad de Granada (España). ricardom@ugr.es \\ Rocío LARA. Universidad de Granada (España). rlo@ugr.es \\ Javier VALSECA. Universidad de Granada (España). \\ javiervalsecadelgado@gmail.com
}

Resumen: Presentamos dos indagaciones preliminares sobre cine y Educación Artística. Primera, un estudio de caso de un niño sobre video espontáneo infantil (VEI) en un contexto familiar en Granada (España), que responde a la pregunta ¿qué vídeos produce la infancia de forma espontánea? Como conclusión inicial a partir de esta observación longitudinal no-participante sugerimos cinco fases: (a) exploración autónoma del aparato de grabación; (b) se actúa delante de la cámara fija; (c) la cámara sigue a la acción, se graba al mismo tiempo que se hace cualquier cosa; (d) imitación directa de sus 'youtuberos' preferidos; y (e) adopción de los usos videográficos adultos predominantes. La segunda es una 'InvestigaciónAcción Participativa' sobre la enseñanza del cine, que responde a la pregunta ¿cómo enseñar a ver y a hacer cine en la escuela? El contexto es un proyecto de cooperación educativa en Educación Artística que desarrollamos en tres escuelas de la ONG 'Asociación Colaboración y Esfuerzo (ACOES) en Tegucigalpa. Las cuatro acciones son: ver películas completas, formación de técnicos proyeccionistas entre el propio alumnado de secundaria, creación de cine de animación a partir de N. MacLaren, en pequeños grupos, y formación del profesorado a partir de obras clásicas del cine español y hondureño. La principal conclusión es que ver y hacer vídeos forma parte del proceso de aculturación en las sociedades contemporáneas por lo que es necesario conocer mejor cuáles son los tipos y modos espontáneos 
de percepción y creación videográfica en edades escolares para poder mejorar los objetivos de aprendizaje del cine en la escuela.

Palabras Clave: vídeo espontáneo infantil, cine de animación escolar, educación artística, cine hondureño y español.

\begin{abstract}
We present two preliminary inquiries on cinema and Art Education. First, a case study of a child on 'children's spontaneous video' (VEI) in a family context in Granada (Spain), which answers the question: What videos does childhood produce spontaneously? As an initial conclusion from this non-participating longitudinal observation five phases can be indicated: (a) autonomous exploration of the recording apparatus; (b) acting in front of the fixed camera; (c) the camera follows the action, recording at the same time as doing anything; (d) direct imitation of its preferred 'youtubers'; and (e) imitation of predominant adult video narratives. The second is a 'Participatory Action Research' on the teaching of cinema, in school. The context is a project of educational cooperation in Art Education that we have been developing in three schools of the NGO 'Association Collaboration and Effort' (ACOES) in Tegucigalpa. The four actions are: watching complete films, training of projection technicians among the secondary school students, making animated films in small groups inspired in N. MacLaren, and teacher training on classic works of Spanish and Honduran cinema. The main conclusion is that watching and making videos is part of the process of acculturation in contemporary societies, so it is necessary to know the spontaneous modes of perception and video creation at school ages in order to improve the learning objectives of screen education.
\end{abstract}

Keywords: spontaneous children's video, making animated video in school, art education, Spanish and Honduran cinema.

\title{
Introducción
}

Presentamos dos tipos de indagaciones sobre cine y escuela. La primera es un estudio de caso en ámbitos familiares sobre las producciones videográficas espontáneas que ha realizado un niño desde los cuatro hasta los nueve años de edad. La segunda corresponde a las actividades cinematográficas que desarrollamos en el currículum de Educación Artística en tres escuelas de primaria y secundaria en la periferia de Tegucigalpa. Esta acción cinematográfica forma parte de un proyecto de cooperación educativa titulado 'BombeArte', que llevamos a cabo entre la Universidad de Granada y la organización no gubernamental 'Asociación Colaboración y Esfuerzo' (ACOES) (http:// acoes.org).

Los objetivos y las metodologías investigación de cada uno de estos dos estudios son muy diferentes porque responden a dos intereses distintos: por un lado necesitamos conocer cómo es la infancia en sí misma, y por otro necesitamos conocer cuál es la 
estrategia idónea para la enseñanza y el aprendizaje de cada contenido curricular específico. Estos dos propósitos son los que han caracterizado la investigación en Educación Artística durante los últimos cien años (Marín Viadel, 2005): ¿cómo dibuja la infancia de forma espontánea? y ¿cómo hay que enseñar a dibujar en la escuela? De ahí nuestro doble propósito: ¿cómo son las producciones videográficas espontáneas de la infancia? y ¿cómo enseñar cine en la escuela?

En los dos estudios partimos de cinco afirmaciones básicas sobre cine y educación, que son una síntesis de las ideas expresadas tanto por autores y autoras contemporáneos (Bergala, 2007; García Martínez, 2007; Marzábal y Arocena, 2016) como por organismos públicos tales como la Academia de las Artes y las Ciencias Cinematográficas de España (Lara, Ruiz y Tarín, 2019) y el Instituto Británico del Cine [British Film Institute (BFI), 2015]: (a) el cine, y en general las narraciones audiovisuales, son uno de los acontecimientos visuales más importantes del arte y la cultura contemporánea y, por lo tanto, deben formar parte de los contenidos fundamentales del currículum de Educación Artística en la escuela; (b) debido a la facilidad tecnológica para grabar video mediante teléfonos móviles y tabletas las niñas y niños que disponen de estos aparatos hacen sus propios videos de forma espontánea (sin supervisión de adultos); (c) el aprendizaje del cine debe de cubrir dos dimensiones, al igual como sucede en la mayoría de los contenidos de Educación Artística: ver y hacer cine; (d) parafraseando a Viktor Lowenfeld (1980 [1947]) la mejor manera de aprender cine es haciendo películas; y (e) la dimensión estética y el placer, emoción y disfrute son elementos ineludibles en el aprendizaje del cine.

\section{Vídeo Espontáneo Infantil (VEI)}

Son los vídeos grabados (y a veces editados) por las niñas y niños entre los cuatro y los diez años de edad aproximadamente, que se hacen sin ningún tipo de indicaciones o colaboraciones por parte de personas adultas. No tiene nada que ver con las niñas y niños 'youtuberos' famosos como 'mattybraps' o niñas cantantes como 'angela vazquez'o 'maddi jane', tampoco incluye los vídeos que hace el alumnado en la escuela con la supervisión de su profesorado, ni tampoco los proyectos participativos o colaborativos de vídeo que se desarrollan en museos de arte o centros culturales, porque en estas investigaciones y experiencias, aunque se concede tiempo para el juego libre con teléfonos móviles, ordenadores y tabletas, el proceso general está organizado y dirigido por los adultos. (Arnott, Grogan y Duncan, 2016; Hatzigianni y otros, 2018).

Video Espontáneo Infantil se refiere única y exclusivamente a los vídeos que hacen los niños y niñas por decisión propia, en la mayoría de los casos en contextos familiares en los que la infancia dispone habitualmente de un aparato de grabación, ya sea teléfono móvil o preferiblemente una tableta, para jugar o, mejor todavía, cuando ese aparato es de su particular uso personal y por lo tanto puede manejarlo a su antojo. 
El concepto de Vídeo Espontáneo Infantil está directamente relacionado con el de dibujo espontáneo infantil, que ha desempeñado un papel crucial en Educación Artística. Desde los primeros años del siglo XX, artistas, educadores y psicólogos centraron su atención en comprender el modo peculiar que tiene la infancia de dibujar cuando se le permite y anima a expresarse con libertad y espontaneidad. Esto transformó los modelos tradicionales de Educación Artística que, en síntesis, cambiaron la copia de láminas por los ejercicios de dibujo libre. (Pernoud, 2003). A pesar de lo controvertido del término 'espontáneo', este sigue siendo utilizado en diferentes ámbitos en las investigaciones actuales: Countryman, Gabriel y Thompson (2016) analizan los sonidos vocálicos diferentes de los establecidos por la lengua materna, a los que denominan 'vocalizaciones espontáneas', que usan los niños y niñas entre 3 y 12 años de edad cuando están jugando en el patio de recreo de la escuela; Richards (2014) usa el término 'experiencias artísticas espontáneas' en su estudio de caso de un niño de cuatro años.

La metodología de trabajo es la de estudio de caso en contextos familiares. Los resultados que presentamos se basan en la observación no-participante de un solo niño, Alejandro, durante nueve años. Según Siggelkow (2007) el estudio de caso tiene tres usos básicos en investigación: motivar subsiguientes preguntas y estudios, inspirar nuevas ideas sobre el problema e ilustrar con un ejemplo concreto cómo puede aplicarse la idea en otros contextos empíricos.

En los vídeos espontáneos infantiles grabados por Alejandro observamos cinco fases. Establecer estas fases es una conjetura en el sentido matemático del término; es decir, es una afirmación de la que tenemos indicios a través de la observación empírica, pero que no ha sido todavía demostrada, ni tampoco refutada.

Primera fase: exploración autónoma del instrumento (desde los cuatro a los cinco años de edad, aproximadamente). Es un momento de familiarización independiente y personal con el aparato o instrumento de grabación. En el caso de Alejandro observamos al menos tres tipos de vídeos en esta fase (Figura 1). Uno, los que corresponden a la simple exploración libre del instrumento. Entre ellos hay brevísimos ensayos sobre el encendido y apagado de la grabación, bastantes grabaciones involuntarias muy largas (varios minutos) en las que el aparato sigue funcionando inadvertidamente, y también giros de la tableta o de la cámara que producen que las cosas y las personas se vean después boca abajo. Un segundo tipo, selfis o autorretratos videográficos, aparecen una vez se ha comprendido el adecuado funcionamiento del aparato, : la tableta funciona como un espejo que o bien se sostiene entre las manos o bien se apoya en una silla o en el suelo y el niño se mira en él. Son muy breves, pocos llegan a los treinta segundos, porque apenas si se desarrolla algún tipo de acción. En tercer lugar, como parte del aprendizaje del aparato aparecen también grabaciones de familiares, mascotas u otras personas en el espacio doméstico. En esta fase no suele revisar por sí mismo las grabaciones. Grabar un vídeo es simplemente una posibilidad que ofrece ese instrumento, sin una conciencia clara de que esa grabación puede ser vista posteriormente. 


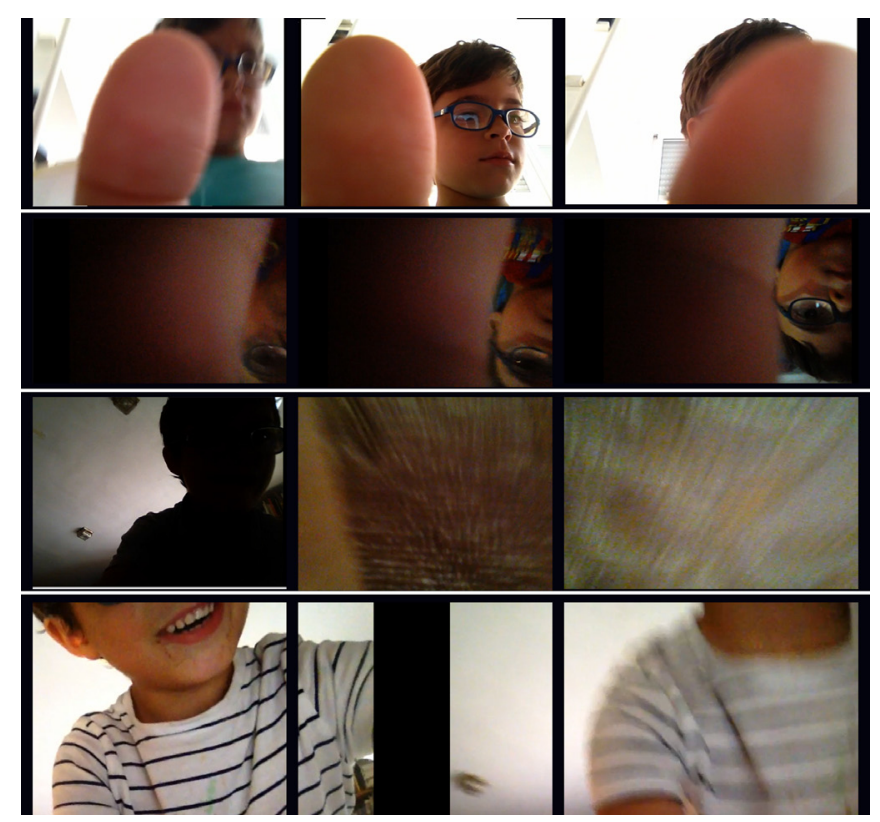

Figura 1. R. Marín Viadel (2018). Colección de cuatro Series Secuencia a partir videos espontáneos infantiles: dedos y cuello. Arriba, Alejandro, cuatro años (2014) [Encender y apagar]. Centro superior, Alejandro, cuatro años (2014) [Tableta volteada]. Centro inferior, Alejandro, cuatro años (2014) [Grabación inadvertida]. Abajo, Alejandro, cuatro años (2014) [Selfi].

Segunda fase: cámara fija ante la que se actúa sabiendo que toda la acción va a quedar grabada (entre cinco y seis años de edad, aproximadamente). Hay un cierto placer en convertirse en protagonistas de la película. Al fin y al cabo es el mismo aparato y la misma pantalla en la que vesus vídeos y películas favoritas y es muy seductor convertirse en la estrella de la escena. También en esta fase es posible encontrar varias clases de vídeos. Un tipo de grabaciones es la de cambiar las expresiones de la cara, hablar, gritar y saltar delante de la cámara. Otro es correr hacia o desde la cámara, en estas ocasiones no siempre se tiene la precaución de que la cámara este situada de forma que registre todo el recorrido de la carrera, por lo que en la grabación únicamente vemos el momento de salida o de llegada. Un tercer tipo es el de hacer cosas o decir palabras que están prohibidas por los adultos: gritar palabrotas y repetirlas muchas veces, escupir, eructar, sacarse los mocos. Estas grabaciones son muy divertidas y representan muy adecuadamente momentos de intimidad. Lo importante no es tanto la grabación sino el hecho de haberse atrevido a exteriorizar ante ese espejo que es el objetivo de la cámara, las cosas que el mundo adulto corrige, reprueba o castiga. 


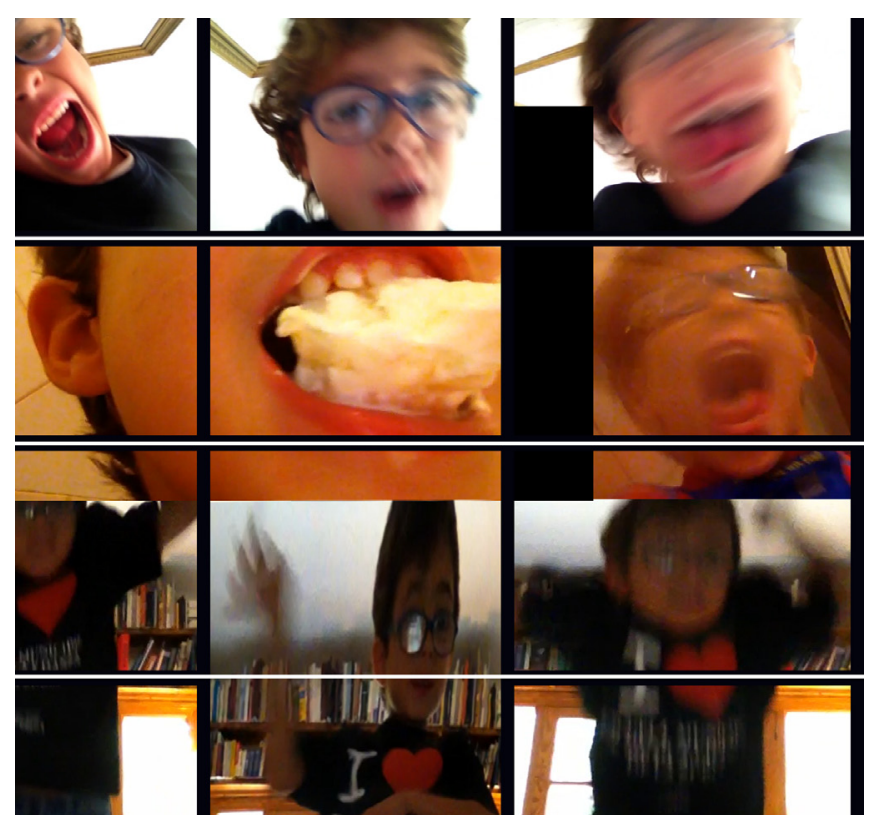

Figura 2. R. Marín Viadel (2018). Colección de tres Series Secuencia a partir videos espontáneos infantiles: gritos y saltos. Arriba, Alejandro, cinco años (2015) [Gritar rock]. Centro, Alejandro, cinco años (2015) [Comer helado]. Abajo, Alejandro, cinco años (2015) [Saltar delante de la tableta].

Tercera fase: la cámara sigue a la acción (desde los seis hasta los siete años de edad, aproximadamente). La cámara deja de estar en un punto fijo y comienza a formar parte de la acción. La acción ya no se desarrolla ante la cámara sino que acompaña y modifica el transcurrir de la acción. De hecho será la grabación la que provoca un recorrido o el gesto o la tarea que se llevará a cabo. No se programan las acciones que se van a grabar, sino que el aparato de grabación simplemente sigue la acción que se realiza: ir a tomar un vaso de leche a la cocina o ir al cuarto de baño. Como estas edades corresponden a los primeros años de escolarización obligatoria, la autonomía y complejidad de las acciones que se van a desarrollar de forma espontánea aumenta considerablemente. Además, en muchos de los juegos y acciones se reclama la participación de los adultos, por ejemplo para salir a la calle a dar un paseo. Y esta participación de las personas adultas implicará también que solicite ayuda para llevar a cabo la grabación.

Cuarta fase: imitación directa de sus youtuberos favoritos (desde los siete a los nueve años de edad, aproximadamente. Inmerso en las modas y modelos que siguen sus amistades se aficionará a los personajes y canales más populares en cada momento. Probablemente llegarán a crear su propio canal para difundir sus propias creaciones videográficas; y de manera semejante a como sucede en sus dibujos, paulatinamente dejarán de confiar en su propia espontaneidad y comenzarán a imitar los modelos visuales predominantes en su ecosistema visual. Uno de los modelos que les resulta más atractivo es el de los youtuberos que graban y comentan sus propias partidas en los juegos interactivos de moda. Imitando el lenguaje (y muchas veces también la indumentaria) grabarán y comentarán sus propias partidas, normalmente situando 
el aparato de grabación en un punto fijo en el que el encuadre los muestre a ellos y ellas y también la pantalla en la que aparece el juego. Comenzarán a producir gran cantidad de vídeos, que duran tanto como la partida que juegan y comentan, con títulos tales como "Hacer un pasadizo secreto y una chimenea en minecraft" y otros semejantes.

La quinta y última fase, a partir de los diez años, aproximadamente corresponde a las narraciones videográficas, habitualmente en grupo, muy semejantes a las del mundo adulto. Hay planificación de las grabaciones, edición sofisticada con las principales opciones de los programas gratuitos de edición de vídeos, así como representación de personajes y situaciones.

Especialmente en estas dos últimas fases es más problemático hablar de espontaneidad por dos razones:los videos corresponden a los modelos visuales imperantes y además, resulta más difícil acceder a las grabaciones, a no ser que hayan sido hechas premeditadamente para hacerlas públicas.

\section{El cine en las escuelas de ACOES en Tegucigalpa}

Las escuelas de la Asociación Colaboración y Esfuerzo (ACOES) fueron creadas a mediados de la década de los años 90 del siglo XX. Están situadas en las colonias o barriadas Nueva Capital, Linda Vista y Ramón Amaya Amador en el entorno periurbano de Tegucigalpa. Su desarrollo fue inverso a lo que prescribe el urbanismo formal: primero se ocupó, se construyeron las viviendas con materiales bastante precarios y paulatinamente se están instalando las infraestructuras y los servicios. Actualmente viven en cada una de estas colonias alrededor de unas cuarenta o cincuenta mil personas. La población procede de otras comunidades marginadas de Tegucigalpa, damnificados del huracán Mitch o de zonas rurales del país. Con trabajos informales e inestables, la mayor parte de la población trabaja sin descanso en jornadas que en ocasiones sobrepasan de doce horas diarias. A esto hay que sumar que casi la mitad de la población no han cursado estudios primarios completos. Son muchas las familias desestructuradas y las madres solteras con un gran número de hijos.

En este contexto lleva implementándose desde hace cuatro años el proyecto de cooperación educativa para la Educación Artística denominado 'BombeArte', organizado por la Universidad de Granada (España). Los objetivos principales del proyecto son: la creación cultural como forma de intervención social, la educación artística y la creación artística contemporánea (http://bombearte.blogspot.com)

Teniendo en cuenta tanto el contexto social de las escuelas como la incardinación de la enseñanza del cine dentro del proyecto de Educación Artística 'BombeArte', tomamos cinco decisiones sobre el modo de enfocar las actividades cinematográficas. 
Una, plantear la enseñanza del cine como una de las principales especialidades artísticas, la más característica del siglo XX, destacando tanto su sentido estético como su componente técnico. El cine es el gran espectáculo audiovisual contemporáneo. Destacar la perspectiva artística significa, por ejemplo, visionar Tiempos Modernos (1936) de Charles Chaplin con cuatro objetivos: (a) embelesarnos con una obra de arte, (b) comprender la evolución del cine mudo al sonoro, (c) aprender a diferenciar entre el sonido y la música diegética e incidental, (d) debatir sobre su crítica social de las sociedades contemporáneas.

Dos, la correcta organización de las sesiones de cine (oscuridad, sonorización, tamaño de la pantalla, etc.) abiertas a toda la comunidad educativa y la adecuación de las obras fílmicas al desarrollo cognitivo y a la potencialidad creativa de los educandos.

Tres, la incorporación del cine en las escuelas como instrumento facilitador de los procesos de enseñanza-aprendizaje y como elemento motivador e interdisciplinar, facilitando el trabajo con contenidos transversales del currículum y la educación en valores. Por ejemplo, tras visionar La novia cadáver de Tim Burton y Mike Johnson (2005) el debate en el cine fórum con el alumnado de secundaria analizó la complejidad y consecuencias de los matrimonios de conveniencia, así como las normas sociales y legales sobre las relaciones de pareja.

Cuatro, la armonización, interconexión y continua retroalimentación entre las sesiones de cine y las demás actividades del currículum de Educación Artística. Por ejemplo, el visionado del corto de animación Dripped, dirigido por Leo Verrier (2009), homenaje a Jackson Pollock, derivó en una acción pictórica participativa al modo del Expresionismo Abstracto.

Y cinco, la necesidad combinar el visionado de películas con la creación videográfica hecha por el propio alumnado.

Como la mayoría de nuestro alumnado en las escuelas de ACOES nunca ha ido al cine, no pudimos evitar asociar nuestro proyecto al de las Misiones Pedagógicas (1931-1939). Este proyecto educativo, artístico y social fue organizado en España durante la Segunda República por el Ministerio de Instrucción Pública y apoyado por el Museo Pedagógico Nacional y por la Institución Libre de Enseñanza. Su propósito fue crear una escuela ambulante que facilitara una experiencia vital sobre la pintura, el teatro y el cine a la población rural que nunca antes habían tenido la oportunidad de vivir estas experiencias. La Figura 4, ofrece una comparación visual entre las fotografías del público rural en España viendo cine por primera vez y las de nuestro alumnado en Honduras. 


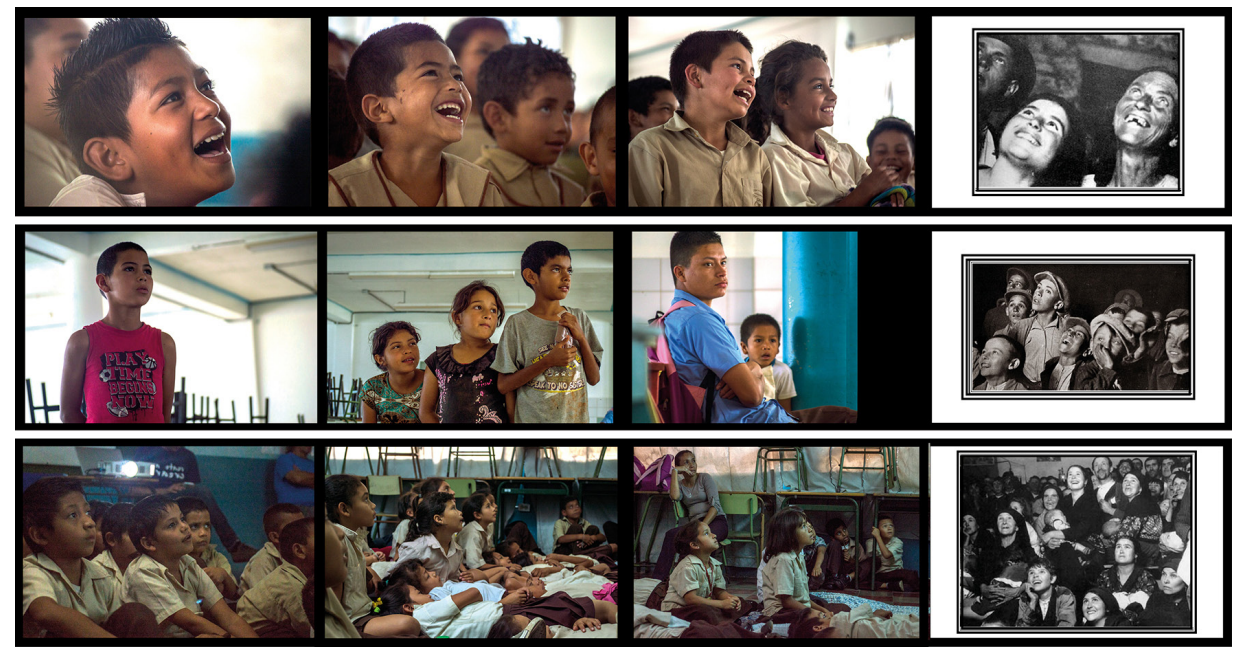

Figura 3. R. Lara (2019) Cine en el proyecto BombeArte, 2017. Fotoensayo comparativo compuesto por nueve fotografías tomadas en las sesiones de cine en las escuelas Santa Teresa y Santa Clara (2017) y, en la columna derecha, tres citas visuales literales atribuidas a José Val del Omar de las sesiones de cine de las Misiones Pedagógicas (ca. 1931-1935).

Pasar de la posición de espectador/a a la de creador/a es uno de las ideas fundamentales en Educación Artística. Utilizamos como referente al cineasta canadiense Norman McLaren (1914-1987), cuyos experimentos en torno a la animación aportan estrategias muy útiles para comprender la técnica cinematográfica. Su cortometraje A Chairy Tale (El cuento de una silla, 1957) fue creada mediante dos procedimientos vinculados a los primeros 'efectos especiales' en el cine: la animación fotograma a fotograma o 'stop motion' y la 'pixilación'.

Una silla escolar puede convertirse en un elemento perfecto para comprender los conceptos fundamentales de la técnica cinematográfica. Primero vimos la película de McLaren y después preguntamos cómo era posible que una silla hubiese adquirido movimiento. La gran mayoría del alumnado de primaria, debido principalmente a su escasísima experiencia con el cine, proponía como solución el uso de imanes o cuerdas para que las sillas se movieran tal y como las habían visto en la pantalla. En realidad esa es la magia del cine y también la del teatro, que se produce cuando tácitamente el espectador acuerda sumergirse en la obra y concederle carta de realidad a la ficción. La intriga entre nuestro alumnado aumentó cuando nosotros mostramos una brevísima película, que habíamos hecho previamente, en la que se movía una de las sillas que había en la clase. Esta pequeña animación nos sirvió para hacerles comprender que la técnica cinematográfica consistía básicamente en una rápida sucesión de imágenes fijas que producen la sensación de movimiento.

El siguiente paso fue la creación de una obra colectiva de animación con grupos de entre ochenta y ciento veinte alumnos y alumnas. El gran tamaño del grupo, que en principio parecía un inconveniente, pronto se convirtió en una ventaja: teníamos a nuestra disposición alrededor de un centenar de animadores/as, para ir moviendo poco a poco los diferentes elementos del mobiliario que había en el aula. Una de 
las películas la hicieron con la técnica de 'stop motion', unas cuantas sillas y una cámara fija. La otra, con la técnica de 'pixilación' tomando a un compañero y a una compañera como elementos de la animación.

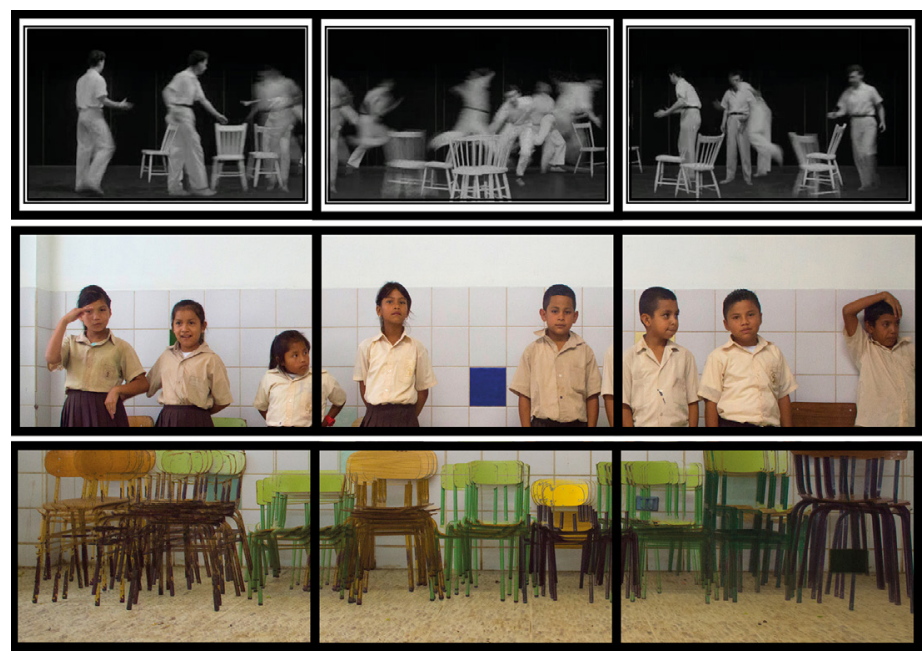

Figura 4. R. Lara y J. Valseca (2018). Sillas, compañeros de clase y McLaren. Fotoensayo compuesto por, de arriba abajo, una cita visual indirecta obtenida mediante la superposición de fotogramas del cortometraje A Chairy Tale (1957), tres fotografía independientes del alumnado participante en la actividad (2017) y una media visual obtenida de la superposición de los fotogramas de la animación resultante (2017).

Para dar continuidad a las proyecciones cinematográficas durante todo el curso escolar (y no solo durante las cinco o seis semanas de duración anual del proyecto 'BombeArte') y para que el cine no fuera una actividad excepcional sino habitual en el escuela, creamos un taller para la formación de técnicos proyeccionistas entre el propio alumnado de secundaria. En cinco sesiones de dos horas de duración, un pequeño grupo de unas doce alumnas y alumnos de secundaria - los más interesados en el cine-, aprendieron a manejar el ordenador portátil, el proyector, el equipo de sonido y la pantalla. Y, sobre todo, a organizar el conjunto de la sesión, desde el anuncio y coordinación de aula y horario con el profesorado, la preparación del aula y del equipo técnico, la presentación de la película y la dinámica del debate posterior a la proyección.

Finalmente, la formación del profesorado es necesaria junto a las actividades dirigidas directamente al alumnado, para desarrollar cualquier proyecto curricular. Los objetivos de las acciones con el profesorado fueron fundamentalmente dos: debatir la importancia de los contenidos cinematográficos en el currículum de la materia de Educación Artística y proporcionarles las herramientas para que pudiesen utilizar el material cinematográfico para generar propuestas de creación de imágenes en el aula. Con este propósito trabajamos a partir de obras clásicas del cine hondureño en combinación con las propuestas didácticas del cineasta granadino José Val del Omar (1904-1982). El cortometraje experimental Mi Amigo Ángel (1962) del cineasta Sami Kafati (Tegucigalpa, 1936-1996) es considerada la primera película del cine hondureño. 
La metodología se basó en las propuestas didácticas de Val del Omar vinculadas al uso de las tecnologías de la proyección en entornos educativos. Su principal objetivo es generar nuevas imágenes a través de la experimentación libre con los recursos tecnológicos disponibles en el aula. (Val del Omar, 1932 y ca.1973). Las propuestas de Val del Omar usan lentes, proyectores de cuerpos opacos y proyectores de diapositivas, que eran las nuevas tecnologías de la imagen en el aula en los años sesenta del siglo XX. Pero lo decisivo de sus ideas es que no quedan reducidas a unos medios tecnológicos ya completamente superados (incluso desaparecidos del panorama escolar) sino que son aplicables al uso de cualquier tecnología disponible para el descubrimiento y la experimentación con nuevas ideas visuales.

Actualmente trabajamos con proyectores y con ordenadores, y por lo tanto la cantidad de imágenes y de obras cinematográficas disponibles en el aula es mucho mayor que hace unas décadas. El foco de interés se centró en la participación activa del profesorado, pasando de ser espectadores pasivos a creadores activos. Con los protectores disponibles podían fundirse las imágenes de Sami Kafati con las de Val del Omar y podían transformarse y deformarse las imágenes moviendo los proyectores por el espacio del aula. Usando los proyectores como linternas en la oscuridad, las imágenes cinematográficas, ya sea en movimiento o con el fotograma congelado, nos permiten descubrir la arquitectura de la sala, creando distorsiones y transparencias dependiendo si dirigimos la imagen proyectada a una esquina del techo, al respaldo de las sillas o a la espalda o el rostro de un compañero. Todas estas nuevas y efímeras imágenes pueden, a su vez, ser fotografiadas y grabadas e incorporarse a las proyecciones, creando de este modo una trama sucesiva de planos superpuestos. Todas estas estrategias visuales ayudan a "contribuir a la evaluación y al avance del uso de las nuevas tecnologías en la educación para lograr nuevas metodologías acordes con el contexto social contemporáneo" (Sanders III, 2006:103).

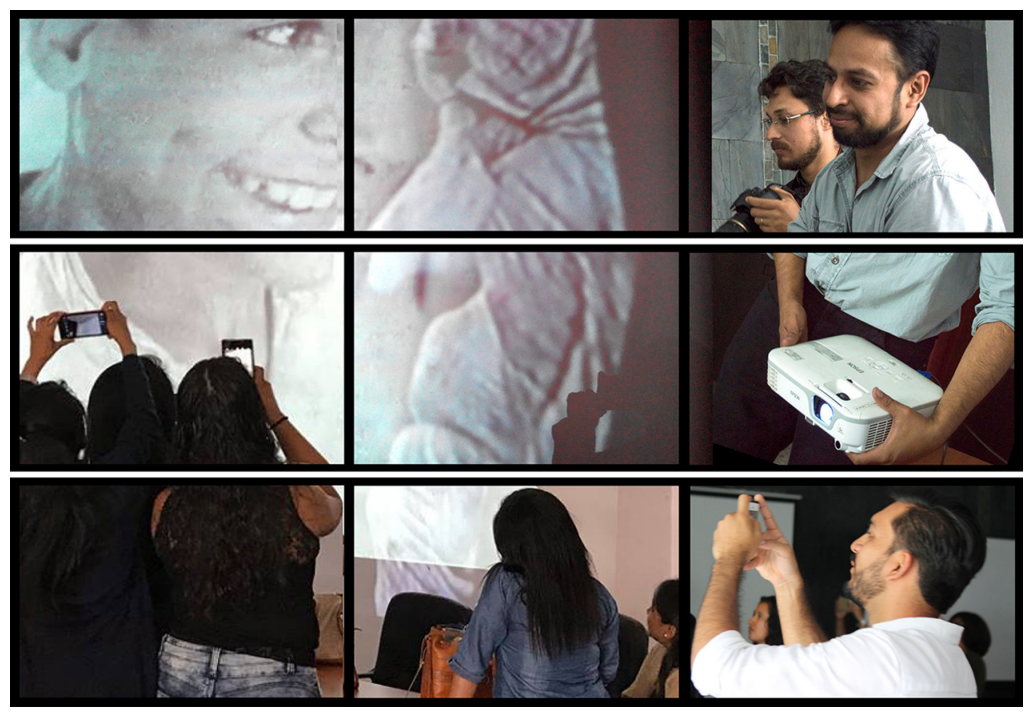

Figura 5. R. Lara (2018). Fotoensayo compuesto por seis fotografías digitales tomadas por el profesorado durante las sesiones de formación del profesorado (2017). 


\section{Conclusiones}

Los hallazgos, aunque incipientes, obtenidos del estudio de caso han sido útiles para encarar las propuestas sobre el aprendizaje del cine en la escuela, especialmente con el alumnado de los primeros cursos de primaria. En los procesos de familiarización con cámaras y tabletas, especialmente entre los que no tenían experiencias previas con estos aparatos, aparecen con frecuencia errores en el encendido y apagado, selfies (personales y de grupo), actuaciones ante la cámara fija, así como grabaciones en las que la cámara sigue la acción. En el estudio de caso, estos procesos se produjeron a lo largo de años, principalmente en función de la edad del niño. En la escuela, trabajando con varios grupos simultáneos de unos cuatro o cinco niños y niñas por tableta, en sesiones de unos 30 minutos, las diferentes estrategias se producen de manera muy rápida. Estas sesiones de exploración espontánea con el aparato de grabación son decisivas para el empoderamiento personal y grupal sobre la creación de imágenes, una porque he sido yo (o mi grupo) quien decido qué cosas grabo y cuáles no merecen mí atención, y dos porque al reproducir los estereotipos predominantes (poses, gestos y miradas ante la cámara imitando los modelos de famosas y famosos), me integro en los modelos culturales hegemónicos.

Ver y hacer vídeos forma parte del proceso de aculturación en las sociedades contemporáneas por lo que es necesario conocer mejor cuáles son los tipos y modos espontáneos de percepción y creación videográfica en edades escolares para poder mejorar los objetivos de aprendizaje del cine en la escuela. Usando un símil con el lenguaje verbal, a la escuela corresponde la lectura, la escritura, la gramática y la literatura de las narrativas audiovisuales.

\section{Referencias}

Arnott, L.; Grogan, D.; Duncan, P. (2016). Lessons from Using iPads to Understand Young Children's Creativity [Lecciones del uso de iPads para comprender la creatividad de los niños pequeños]. Contemporary Issues in Early Childhood, 17 (2) p. 157-173.

Bergala, A. (2007). La hipótesis del cine: pequeño tratado sobre la transmisión del cine. Barcelona: Laertes.

British Film Institute (BFI). (2015). A framework for film education [Estructura para la educación cinematográfica]. London: British Film Institute. Recuperado de https://www.bfi.org.uk/sites/bfi.org.uk/files/downloads/\%20bfi-a-framework-forfilm-education-brochure-2015-06-12.pdf

Countryman, J.; Gabriel, M.; Thompson, K. (2016). Children's Spontaneous Vocalisations during Play: Aesthetic Dimensions [Vocalizaciones espontáneas de los niños durante el juego: dimensiones estéticas]. Music Education Research, 18 (1) p. 1-19. 
Duncum, P. (2018). Drawing in art education research: A literature review [online]. Australian Art Education, 39 (2) p. 223-235.

García Martínez, A. (2007). Infancia, cine y educación. Murcia: Diego Marín.

Hatzigianni, M.; Gregoriadis, A.; Karagiorgou, I.; Chatzigeorgiadou, S. (2018). Using Tablets in Free Play: The Implementation of the Digital Play Framework in Greece [El uso de tabletas en el juego libre: la implementación de la Estructura Digital de Juego en Grecia]. British Journal of Educational Technology, 49 (5) p. 928-942.

Lara, F.; Ruiz, M. y Tarín, M. (Coord.). (2019). Cine y educación. Madrid: Academia de las Artes y las Ciencias Cinematográficas de España. Recuperado de https://www. academiadecine.com/wp-content/uploads/2019/03/Cine-y-Educacio\%CC\%81n. pdf

Lowenfeld, V.; Lambert Brittain, L. (1980 [1947]). Desarrollo de la capacidad creadora. Buenos Aires: Kapelusz.

Marzábal, I. y Arocena, C. (2016). Películas para la educación: Aprender viendo cine, aprender a ver cine. Madrid: Cátedra.

Marín Viadel, R. (coord.) (2005). Didáctica de la educación artística para primaria. Madrid: Pearson.

Pernoud, E. (2003). L'invention du dessin d'enfant en France, à l'aube des avantgardes [La invención del dibujo infantil en Francia en el alba de las vanguardias]. Paris: Hazan.

Richards, R. (2014). The Private and Public Worlds of Children's Spontaneous Art [Mundos privados y públicos del arte espontáneo infantil]. Studies in Art Education: A Journal of Issues and Research in Art Education, 55 (2) p. 143-156.

Sanders III, J.H. (2006). Performing Art-Based Educational Research: An Epic Drama of Practice, Precursors, Problems and Possibilities [Investigación basada en Artes: un drama épico de prácticas, precursores, problemas y posibilidades]. Studies in Art Education. A Journal of Issues and Research. 48 (1), p. 89-107.

Siggelkow, N. (2007). Persuasion with case studies [Persuasión con estudio de caso]. Academy of Management Journal, 50 (1), p. 20-24. Recuperado de http://w. aom.org/uploadedFiles/Publications/AMJ/Siggelkow.2007.pdf

Val del Omar, J. (1932). Sentimiento de la Pedagogía Kinestésica. [Documento mecanografiado]. Madrid: Archivo Valdelomar. Caja Conferencias, No reg. 1553. Recuperado de http://www.multidoc.es/Archivo_en_linea/184.pdf. 
Val del Omar, J. (ca.1973). Enosa, el niño y los instrumentos educativos para experimentar en directo. [Documento manuscrito] Madrid: Archivo Valdelomar. Caja Enosa Adiscopio, No reg. 1028. Recuperado de http://www.multidoc.es/ Archivo_en_linea/92.pdf.

\section{Agradecimientos}

Esta investigación ha sido posible gracias a un Proyecto $\mathrm{I}+\mathrm{D}+\mathrm{i}$ del Ministerio de Ciencia, Innovación y Universidades del gobierno de España, referencia HAR201676353-R, titulado 'Métodos artísticos y visuales de investigación, innovación educativa e intervención social. 